\title{
A CONVERSATION WITH
}

\section{Giuseppe Civitarese}

\section{Conceição Melo Almeida Bruno Raposo Ferreira}

1

Psicanalista Titular com funções didáticas na Sociedade Italiana de Psicanálise (SPI), Membro da American Psychoanalytic Association (APsaA) e da Associação Psicanalítica Internacional (IPA).

2

Psicóloga Clínica e Psicanalista. Membro Titular da Sociedade Portuguesa de Psicanálise (SPP) e da Associação Psicanalítica Internacional (IPA).

\section{3}

Psicólogo Clínico e

Psicoterapeuta. Membro

Candidato da Sociedade Portuguesa de Psicanálise (SPP).

\begin{abstract}
Giuseppe Civitarese, is a psychiatrist and one of the leading psychoanalysts on the Italian and international scene. His frequent and consistent contributions to the development of the theory and practice of post-Bionian analytic Bi-personal Field Theory (BFT) occupy an important place in contemporary psychoanalysis. He has lectured in Italy and abroad and published extensively on several topics. Giuseppe was editor-in-chief of Rivista di Psicoanalisi, the official journal of the Italian Psychoanalytic Society. Some Italian colleagues describe Giuseppe as an affectionate, meticulous and rigorous person, committed to the study of psychoanalysis, whose teaching he is truly passionated. We know he is also passionated by philosophy, visual arts and literature. Reading his work one gets the impression that he carries a deep appreciation for the openness and depth of the psychoanalytic encounter. In this interview Giuseppe kindly talks about different aspects of his thought. Our conversation was led by his generous and sincere way of sharing ideas.
\end{abstract}

CMA: Dr. Giuseppe Civitarese, you live and practice in Pavia, Italy. We know you were born in the beautiful Italian region of Abruzzo and that you came to Pavia to study. Can you tell us something about this journey, and how did psychoanalysis cross your path?

GC: Psychoanalysis crossed my path for the first time when I was 14 or $13 .$. in Italy it is the stage before high school, between primary school and Liceo Classico, which is high school. So, I had this teacher of science and maths. He was very young, younger than 30 years old and he had just graduated from Bologna University. He was enthusiastic about his work and about culture in general. He was very clever and had humble origins, for him culture was the way to affirm himself. So he wanted to transmit this. He was the kind of teacher who is able to start good relationship with students and he liked to talk beyond science and biology, about all important figures in the history and culture. It could be Descartes, Marx, Pascal. It could be this weird guy that could interpret dreams, a certain Freud. And I always loved books. I was very happy when people in the family gave me books as a gift. In my family my father could only do a few years of school and my mother only a few more. So, I was somehow in the same position of this teacher. In the end I bought the Interpretation of Dreams and of course I immediately realized that it was too difficult. But since then I began to pay attention whenever psychoanalysis was mentioned in the newspapers, on TV, etc. Then, step by step, I discovered Freud's easier books on jokes, on the psychopathology of everyday life, etc. and read them. Over time, this grew more and more.

At the time, in Italy a famous figure was that of Franco Basaglia, the one that in Italy closed our mental hospitals, the leader of 'anti-psychiatry'. This 


\section{As a psychiatrist, I worked for six months in my first job in a psychiatric hospital. It was like a lager. The only good thing we could do was to close them down. These were places where insanity was produced. There is no way to cure someone by locking them up and erasing them in a mental hospital. It is completely impossible.}

was now high-school, and there was a convergency of my political leftist ideas and my interest in psychiatry and psychoanalysis. During my last year at high-school I had also the possibility to meet with Basaglia, as he came to Chieti to give a conference. I was very impressed by his personality. So before going to the university I already had a strong interest for psychoanalysis and for psychiatry. Of course, you can imagine that if I was more interested in Freud than in Blaise Pascal, which I also read, it was because, I don't know, puberty and sex were there somewhere and I already had a certain inclination to introspection... and at that time I had some physical health problems that kept me isolated from some activities at school like sports, a beginning of articular rheumatism that, as you know, can affect the heart. That was completely overcome, but of course for a while it wasn't easy.

Then I came to Pavia because it's an old university town. It is there since the XIV century, and there are very old collegi, and it is still the best, or among the best faculties in Medicine. Still, my first choice had been Rome which is the town that I love above all the others, but I couldn't get in the private university that I chose in Rome, the Catholic University, because at the time in public universities there was a lot of chaos. These were difficult times with the Red Brigades, terrorism etc. And I needed to study, I wanted to study. In the end it couldn't be the Catholic University in Rome, that admitted only a very limited number of students. So I came to Pavia. Coming to Pavia it was like landing on another planet because I found people very different from people from the center or south of Italy, which are warm and very welcoming. Here people are a more reserved. Sometimes I think that it is because in winter there is a lot of fog, and there is some fog also in their mind and around them. I'm joking. Another explanation is that I had this kind of illumination one day, while I was going from Pavia to Milan by train: here everything is flat, it is the pianura padana, so for this very pragmatic people it is very easy to go from point $\mathrm{A}$ to point $\mathrm{B}$, they don't have to use their imagination. On the contrary, in the center of Italy there are hills and mountains everywhere... in Abruzzo, even if my birthplace is near the sea, you need to use your imagination to go around. These are jokes, in the end it was very good to come here. In fact, I'm still here even if coming away from my region was painful at the time. It's 600 $\mathrm{km}$, the train took ten hours. It never ended.

BRF: Are you talking about the seventies?

GC: Yes, I was born in 1958 and came here in 1977. It was the worst time of this crazy political-terrorist period. I'm ridiculously attached to Abruzzo, to the center of Italy, to the South, it's my neurosis, you know. I always make jokes about Abruzzi people being smarter... my compatriots are Ovid, Croce, D'Annunzio... nicer and warmer. Every time I meet someone from Abruzzo, Campania or Lazio who is not nice, it is a shock to me because my theory is not confirmed. So... in the end I adapted to Pavia, but it's still a wound, this is very psychoanalytic, I feel this strong bond. Obviously my attachment to the mother must be very strong, I would say. And that involves organizing all the time the transportation of oil, wine, pasta, tomatoes and mozzarella from the South to the North. When I came here, I didn't know what kind of people I would find in psychiatry, and even for a while in my medical studies I considered other kinds of specializations. But in the end, my old interest in psychiatry and psychoanalysis prevailed and that was very good.

At the time, the Pavia school of psychiatry was famous for its psychoanalytic orientation. My teachers were among the best psychoanalysts in Italy and so I grew up in my ideal environment, given my interests. Perhaps that's one of the reasons I'm still here, because all along the way I made strong connections with these people. Another good thing about Pavia, besides the fog, the flatness, the evil cold and the mosquitoes, is that it's close to Milan. It's thirty kilometers, it's the ideal small university, calm and quiet, like Coimbra, Oxford, Salamanca, but in thirty minutes I leave my house and I can be in Piazza Duomo, near La Scala in Milan. There you can find everything you need. Also, 
my psychoanalytic training was in the Milan Psychoanalysis Center. Now we also have a small one in Pavia. But at that time, everything was in the big city.

CMA: In a certain way it seems the trigger was The Interpretation of Dreams.

GC: Yes. Well, of course this is one of the books that has changed humanity and human culture. We can say today that with Bion, for example, who interestingly enough joins Jung in some ways, because his conception of dreams is very similar to Jung's, we have changed the way we look at dreams. Think also of Meltzer. His Dream Life, it's a good book. However, The Interpretation of Dreams is always there. It will always remain there, because Freud is a classic, he is a genius and we will always come back to this book even though our conceptions of dreaming and dreams and our technique for many of us has changed. But this is a huge book. Sometimes people don't realize the epigraph of The Interpretation of Dreams, which is "Acheronta movebo". In Italy it sounds very Dantesque. Freud says 'I will be your Virgil and take you on a journey to hell'. When you cross the river Acheron you are in hell. This is a quote from Virgil. So it's really Freud saying, 'I will be your Virgil, you will be my Dante and we will engage in this adventurous journey'. This is beautiful. This is great, although I no longer see Ucs as hell, rather the opposite. Several others among Freud's books will remain as unforgettable classics, especially Beyond the Pleasure Principle and Civilization and its Discontent. Anyway, yes, you're right, the beginning was with dreams, and after a lifetime in psychoanalysis working with dreams I still find them amazing, amazing every day, it's amazing what a dream can accomplish, so yes, it is.

BRF: It seems that relationships with teachers were very important to you. We know that you did two personal analyses, that one of your supervisors was Antonino Ferro. How have your initial relationships with colleagues, influenced the way you work today as a psychoanalyst?

GC: Yes, you are right. I found out very early on that you learn through relationships, not just by acquiring information, otherwise we would put a computer in there, right? In school, every time, it's all about relationships. I think throughout your schooling, from elementary school to college to grad school or whatever, if you find one and a half teachers (if you're very very lucky, maybe you find two and a half) who engage you in the way I described earlier, and those kinds of relationships will nurture you for life. I've been very lucky. I've had two and a half, maybe three. One of them was only a teacher of mine for one year in elementary school when I was eight years old. He was incredible. Then there was the science and math teacher that I've already mentioned. And then, the Greek teacher in higher education, who was also a very charismatic person. Once in college, at that time, there was not a limited number of enrollments in medical courses. In the beginning here in Pavia there were thousands of us, so you were a number. This was a shock to me, because in my small town in Abruzzo I was well known and felt recognized. I always did more than well in school, because I loved to read, I loved to study and it was all very natural for me. But here, in Pavia, I was just a number. A complete stranger for at least five years. I had friends, sure, but I was suffering a little bit. It only ended when I started my clinical experience in the psychiatric ward as a medical student. At that time, I asked a professor to guide me in my thesis in psychiatry, that was about psychiatric dialogue. And that was again the time when I was able to benefit from relationships, as you said. At that stage of my training I was in a very good climate, among good, intelligent people who were very passionate about psychiatry and psychoanalysis. Not like Basaglia, but on the same line against asylums. I know from experience what they are like. As a psychiatrist, I worked for six months in my first job in a psychiatric hospital. It was like a lager. The only good thing we could do was to close them down. These were places where insanity was produced. There is no way to cure someone by locking them up and erasing them in a mental hospital. It is completely impossible. However, along the way 


\section{The most valuable thing we have inherited from our 'maestri' in the school of psychiatry is a deep human respect for the sick person, even the most regressed. Psychiatry and psychoanalysis are meaningless, and indeed can be easily perverted, if they do not have at their core a strong ethical tension.}

these teachers turned out to be very influential and then I started publishing with them. I came pretty early on to have about sixty articles in psychiatric journals. But at the same time, I was so interested in psychoanalysis that I ended up not pursuing a college career, even though I could have easily done so after I got my Ph.D.

Ferro was gone when I was an intern in psychiatry. I met him later when I was looking for a supervisor for my second training case. Of course, I knew him by name, but I still remember talking enthusiastically with my analyst about Ferro's most important book at the time, The Bi-Personal Field: Experiences in Child Psychoanalysis. So, it wasn't that I met Ferro and became committed to the kind of psychoanalysis he was developing because it was simply there. No. In fact, I chose him. I was already passionate about his ideas. Then I did six years of supervision with him. After the first few years I was always surprised that I didn't understand what he was telling me, 'How come I still don't see the point?'; and also, I couldn't understand how he could love Bion so much. And now that I teach and supervise, when young colleagues after a few times tell me 'Giuseppe, it's too hard, I don't understand', I go back to my memories. It took me a very long time to get to know Bion's ideas and BFT. Then after these six years, of course, step by step, we also became friends and shared many things, and still recently we published a new book called Playing andVitality in Psychoanalysis, which will be available also in English next year from Routledge.

Well, these links, not only Ferro of course, but also other friends of mine, who are psychoanalysts around here, more or less of my age, Fulvio Mazzacane, Maurizio Collovà, Elena Molinari, and many others. So, Pavia is still a great place for psychoanalysis, not so much at the University, as it used to be. But now that we have a psychoanalytic center, somehow around here there is a very good ground for psychoanalysis. The most valuable thing we have inherited from our 'maestri' in the school of psychiatry is a deep human respect for the sick person, even the most regressed. Psychiatry and psychoanalysis are meaningless, and indeed can be easily perverted, if they do not have at their core a strong ethical tension.

BRF: You like to situate yourself as a post-Bionian psychoanalyst within the framework of intersubjective and BFT. Since we can recognize different models of field or intersubjective theories in psychoanalysis, we would like to ask if you can distinguish what are the main aspects of your approach?

GC: I can share with you a couple of things that usually help me situate where I am theoretically, so to speak. In doing so, I like to point out the shifts between paradigms but also the continuities. I try to outline some continuities so that we can be able to maintain a dialogue with each other without barricading ourselves in a dogmatic theoretical position. If we look at the history of psychoanalysis, we easily find a red thread running through all the major perspectives and theoretical models. From time to time, with each new influential author, a new conceptualization of the unconscious emerges. In general, what we realize is that, gradually, a little more of the analyst's unconscious is brought into the analytic room. This is the red thread of psychoanalysis. Initially, Freud explains to patients what their unconscious does and does not do. Later, he realizes that this is not enough and that there is a need for experience; that the patient needs, as it were, a new experimental neurosis, which is the transference neurosis. A purely cognitive approach does not work. Then, he realizes that it is not only the transference that matters, but also the countertransference. So, the analyst gets into it a little bit more. With Klein, the projective identification takes in a little bit more of the analyst, because you are no longer just a screen, and something happens within you. Then we have the concept of enactment, in which the analyst admits that at least for a period, short or long, he does not know what he was doing, and that unconsciously he may have been trapped in a game, the meaning of which he will discover eventually, if and when he "wakes up" from it. Then, 
we have all the different kinds of third parties or thirdness... But these are still circumscribed in space and time. Besides, all these new theoretical devices are still used to reconstruct and understand the patient's past. When one wakes up from the enactment, it is still directed towards the past. It is like a time machine. You have unconsciously acted in a play that was written by the patient. You were just an actor in the rehearsal of an episode from someone else's past life.

Finally, we have the concept of the field. The field is a model whose basic postulate is that, at any time, when we are in proximity to another person, unconsciously there is something that is jointly created, which cannot be isolated and said 'that belongs to one or the other'. Once a field is generated, you can't split off the emergent properties that characterize it. So, this is the metaphor that we always use to look at this unconscious 'common' layer, a kind of dynamic Gestalt field. At any given time. It's not limited in space and time, like the notion of the intersubjective third, it's not limited like enactment, which happens at certain times and refers to the patient's past. No, you are always there in the field, spontaneously engaged with the patient and vice versa. So, this is a way of going beyond the you and me split, which is still relational. Let's pay some attention to that. A true 'relational' approach is one that still describes how I give you something, you give me something else, you attack or seduce and vice versa, I defend, etc. No, this is still not the field... The starting postulate of the field is that there is this layer where it is not possible to say, at this level, what is yours and what is mine. It's like in quantum physics: there is no isolated particle, only waves and vibrations in the field. So, you see, I think this is the most radical way to bring the analyst's unconscious into the "game of psychoanalysis," as Bion calls it, but it can still be seen as an end of the red line... But why do we change our concepts? We change because at some point our community or at least an important part of our community thinks that the new concepts somehow help us more and better to understand what is going on in analysis, even if we cannot give a mathematical demonstration of it. It's a matter of internal dialogue in our community. Now, if you look at psychoanalysis around the world, the relational paradigm is prevailing in all its different forms, in South and North America, in Europe... There has to be a reason for that.

You see now the direct link between what we said about my biography and the relevance of the relationship in school to what I am interested in?... I think the "big bang" was around the early 1960s when Winnicott said that "there is no such thing as a child" unless you consider it with the mother. Bion said the same thing, not 'as a pediatrician', but because of his work on groups. In a sense, for Bion the subject is a group, internally it is structured as a group. So, they both said the same thing, but coming from different places. They all quote Winnicott's phrase, or the way Bion translates it, for example, when he says that an emotion has no meaning outside of a relationship - that's why

As human beings we are living paradoxes. As subjects, we have a subjectivity and intersubjectivity dialectically linked to each other. for Bion an emotion is already a kind of primordial type of a mental concept that arises from a negotiation within a field. So, you see, this is the big bang. Everyone quotes this Winnicott quote a lot, but not everyone asks, 'What is he saying and why?'. Because, if we think it's revolutionary in some way, then we have to ask why. Yet, many of our colleagues quote this Winnicott's quote but continue to work classically. So, there is a contradiction there. I think we need to be consistent. If we quote this phrase, it is because there is something new. If there is nothing new, why do we give it so much emphasis?... Approaching my own conception of BFT... I was seduced by the way the notion of field makes our work come alive again, but the problem is you can't integrate BFT with an epistemic paradigm in psychoanalysis marked by suspicion...

Now, when I go around teaching, people always ask me what the difference is between BFT and intersubjectivity. It's not that I necessarily wanted to talk about intersubjectivity. Ferro never uses that word. It's out of his lexicon. I got interested in intersubjectivity because people ask me about it. Well, of course, you also know that in the United States there are psychoanalytic models that 


\section{There is another paradox here.}

BFT, which is hyper-relational, can also be called anti-relational if we consider that it goes beyond the traditional I/You division. This has significant technical implications, particularly in the way of listening. I can anticipate that for me this aspect is very important, because it helps us to approach an ethical refoundation of psychoanalysis. In fact, I think we need to move beyond the suspicious attitude in the way we listen in analysis. call themselves 'intersubjective'. I say intersubjective or intersubjectivism, it's an ambiguous term. Because it suggests to you the interaction, what happens between two. But this for me is not enough, because if we take the concept of intersubjectivity that belongs to the speculative discipline, to philosophy, to Husserl or even to Hegel, even if he never uses this word, and we bring it to psychoanalysis, there must be a reason. Otherwise, why? The only reason I see is that if you take it from Hegel you have to stick consistently to his theory of the dialectic of recognition which explains how you become a subject.

If you take it from Husserl, you should understand what Husserl came to think of intersubjectivity as this common and shared transcendental layer of being, which is pre-reflective, but later also linguistic-reflective, and of the fact that only then did he come to think that he could explain why I have access to the other and vice versa. Thus, the concept of empathy, for example, is not sufficient because it already presupposes what is yet to be explained, that is, how one accesses the other. Of course, this is perhaps a philosophical question. Instead, for some authors, who do refer to it, the concept of intersubjectivity need not be consistent with Husserl's principle of intersubjectivity, but only with a greater sensitivity to the unconscious participation of the analyst in the analytic process.

The point is that this development of Husserl's idea can be found in his manuscripts and unpublished writings that have only become available over the years. Do we need to make a difference between simple interaction and intersubjectivity? What might be a way to better conceptualize the concept of the unconscious as a field that is created socially, politically? As human beings we are living paradoxes. As subjects, we have a subjectivity and intersubjectivity dialectically linked to each other.

So, for me what's interesting is to develop this kind of intersubjectivity, not just stick to the interaction between subjects, but that kind of phenomena that is the unconscious (transcendental) common layer. It is true that we have to accept the fact we will continue to use the term intersubjective either at a descriptive level, to say interaction, or at a metapsychological or ontological level, and then we are at Husserl and Merleau-Ponty. My effort is to provide more ontological/metapsychological substance to the concept of field.

There is another paradox here. BFT, which is hyper-relational, can also be called anti-relational if we consider that it goes beyond the traditional I/You division. This has significant technical implications, particularly in the way of listening. I can anticipate that for me this aspect is very important, because it helps us to approach an ethical refoundation of psychoanalysis. In fact, I think we need to move beyond the suspicious attitude in the way we listen in analysis.

BRF: You seem to be pointing to something Merleau-Ponty develops when he refers to a sort of layer that sustains our way of being with the other, which is a strong reference for field theory. Can you elaborate on how this way of co-being translates into analytic listening, and the way you think about narrativity and emotional exchange between the analytic couple?

GC: I will try to be schematic because there is always a lot at stake. I always remember that Ludwig Binswanger, the great psychiatrist and father of existential psychotherapy, said that the Cartesian vision of the subject, the split between mind and body, and between subject and object, is the cancer of psychology. We also know that all the great philosophy of the entire last century wanted to go beyond this Cartesian vision. So, there is Husserl, of course Heidegger who was his student, although they split, and then Merleau-Ponty - I think he became Merleau-Ponty precisely because he was able to read Husserl's unpublished manuscripts in the Leuven archive-and then Derrida, and so on. So, you see, the great tendency of philosophy in the last century was ultimately what? I think it was to theorize the field in several scientific domains. When Heidegger says that we are not just monads, but that we live in an environment, in constant exchanges with the environment, he was 


I think psychoanalysis should be
the art of giving hospitality to the
Other, and not playing Sherlock
Holmes by suspecting that the
other is the culprit. Sometimes we
say that we ally ourselves with the
healthy part of the patient against
the sick part. But in the end, with
transference interpretation, every
time we disconfirm the patient's
perspective and say "OK, I'll tell you
what really happened".

trying to overcome the Cartesian division between subject and object. He was trying to cure the cancer of psychology that Binswanger talks about. That's why I love reading some of these philosophers because they help us refine our conceptions. And because they too have benefited from the contributions of psychoanalysis - think of Derrida, Ricoeur and others.

I really enjoy intertextual dialogue with other disciplines, but it has to be between equals. It must not be a dominating relationship, which is what is happening today in the relationship between psychoanalysis and neuroscience, which undermines the specific epistemic and clinical contribution of psychoanalysis.

Thus, the notion of field was introduced into psychoanalysis by the Barangers. In the Barangers' first article, in the early 1960s, they cite neither Bion nor Merleau-Ponty. In this article they quote only Kurt Lewin. But this article was republished a few years later and then if you go back to see the two versions you no longer find Kurt Levin, but you do find Merleau-Ponty, and also Bion. At this point you can say that the idea of the field was influenced not only obviously by Klein, but also by Bion and Merleau-Ponty. I think that before going to Argentina, Willy Baranger must have had a philosophical training in Paris.

Now, let's see what I mean by overcoming the suspicious attitude in psychoanalysis. You know that Ricoeur said that Freud, along with Marx and Nietzsche, belongs to the school of suspicion. And this comes largely from the positivist position in Freud's attitude, from the fact that very fundamentally Freud's conception of the unconscious is that it is the wild cauldron of dirty things, of primitive desires and immoral drives, a kind of Dantean hell. In fact, even in our current institutions, if a colleague makes a slip of the tongue, another can respond with "I caught you," "I saw," "now I know what your immoral desire is". As Kernberg says, this is a way of establishing a relationship of dominance. I am not trying to say that the positivist perspective is not legitimate. What I am trying to say is that it is very easy for this suspicious attitude in listening to the other to be infiltrated by the ideology of the listener.

On the contrary, I think psychoanalysis should be the art of giving hospitality to the Other, and not playing Sherlock Holmes by suspecting that the other is the culprit. Sometimes we say that we ally ourselves with the healthy part of the patient against the sick part. But in the end, with transference interpretation, every time we disconfirm the patient's perspective and say 'OK, I'll tell you what really happened'. I don't like this approach anymore; now we have a completely different understanding of what the unconscious is. Here we can only say it briefly with some simplification.

We no longer think of the unconscious as hell but, as Bion says, as the psychoanalytic function of the personality. A 'device' that gives us in some way the possibility to make sense of our experience, or better, sense and meaning, implicit and procedural sense and linguistic conceptual meaning. This is why, for example, Merleau-Ponty says that perception is the unconscious, because we already put everything of ourselves into the perceptual process... our hallucinatory activity, that is always there, our memories, our body, everything. With this completely different idea of the unconscious, of course the technique changes as well. To give an example, what is important for us, from a Bionian point of view, is to understand whether or not the emotional climate of the session is conducive to the development of the mind. The focus is whether and how minds come together in the here and now, because we now have a clearer understanding of how minds are born.

For example, in the relationship between mother and child, even when the child does not understand the meaning of words... Infant in Latin means one who does not speak. This is the main issue, how can we promote the growth of the psyche in someone who does not understand words? You see, if we ask ourselves this, we immediately cut out the more cognitive part of our theories. Still we need to be aware that when the mother interacts with an infant, they are already in the symbolic register, because language and symbolic meanings 


\section{What happens in field theory? The big difference is that as analyst I take responsibility for the disappointment, for the quality of this emotion. It is not yours alone, or mine alone, but it results from our being together... if it is ours, therefore, I can only trust in our common effort and in our more or less effective ability to transform raw emotions (beta elements) into meaningful emotions (alpha elements).}

are brought into this realm by the mother, and then inevitably pervade all the field. But from this point of view, we can no longer see the mother as separate, because otherwise you can't understand anything that's going on. What does "there is no such thing as the child" mean, after all? It means that we have to see the bond and the field that mother and child form together. And it's the same if you are working with an adult. The central point is: does the affective climate foster the growth of the mind and bonds or not?

To give an example, think of a child growing up in a family where hate and anxiety almost always prevail. His development will be terribly inhibited. A session is the same thing. In every minute, the analyst should be able to sense the atmosphere: using Bion's jargon, whether there is hate $(\mathrm{H})$, love $(\mathrm{L})$, or knowledge $(\mathrm{K})$. Since $\mathrm{K}$ can go toward $\mathrm{H}$ or $\mathrm{L}$, it is ultimately a matter of $\mathrm{H}$ or L. It is always dialectical in the end. How can we know what the weather is there? We don't, and we can't directly. We can only listen to what we have available to us in the session, mainly the conversation, but also what accompanies it, sensations, emotions, actions, reveries.

Then, what is the postulate that guides the listening of the unconscious? Again, the postulate is that if the analytic theater is working, if the setting is safe, if there is no fire in the theater, then virtually everything that happens at the common, transcendental or unconscious levels is co-generated...

A patient says, 'Yesterday, I was so disappointed because I had planned to go to the theater in Milan, but the highway was closed'. Is the narrative in itself important, or rather the emotion it reflects? The emotion is important to us, to try to understand the link, the connection that links us in a given moment. What might the patient be expressing? So, here we have a frustration, there is the representation of an obstacle. The analyst should use his compass, which is his own concept of the unconscious. What is this patient unconsciously telling me? In the classical model, does this narrative reflect a transference? Or does it allow me to intuit the presence of some projective identification going on? Or perhaps I should pay attention to how I am feeling right now? Is there something that I don't yet understand but that indicates some possibility of enactment that may become clear in the future?

Or, if we come to BFT, it doesn't matter if you read the text of the session or I read it. The "text' might even be a reverie of mine, which most of the time I keep to myself. But if the postulate is that practically everything belongs to the field because it is co-generated at the unconscious level, that it means that frustration from this point of view is the feeling that belongs to both of us, it is ours, not just yours, or mine. I infer that I myself for some reason feel the patient's feeling of disappointment. Is this emotion that we share conducive or not to being in unison, to somehow arriving at an effective synchronization, which in this model is the factor that produces order and makes our minds grow? I would say no. Somehow, I have to reopen this metaphorical highway so that we can go to La Scala in Milan and enjoy the show together.

In this way, you stop studying the patient and telling him that he unconsciously is experiencing us as an obstacle because of his past; or à la Klein, that he is seeing me through the glasses of an unconscious fantasy, active at the moment, when an obstacle arises between him and satisfaction, and that it would be a breast that is not available. What is the big difference with the field? What happens in field theory? The big difference is that as analyst I take responsibility for the disappointment, for the quality of this emotion. It is not yours alone, or mine alone, but it results from our being together... if it is ours, therefore, I can only trust in our common effort and in our more or less effective ability to transform raw emotions (beta elements) into meaningful emotions (alpha elements). So it's us, who are now trapped or stuck in a place where we are breathing air intoxicated by hate, anger, envy, etc. If I listen in this way, I am already beyond the I and You split, not suspicious of the patient, and trusting his and my unconscious at work.

This reversal of perspective, as a relational experience, is already therapeutic in itself. The result, I think, is that we're less exposed to the risk of a kind of 
very subtle ideological infiltration, which means that often with good intentions we run the risk of judging the other, diagnosing the other, disapproving of the other, perhaps implying that if they don't change it's their business... or they have some kind of primitive destructive core, so to speak, that makes them wrong. Well, do you see how the technique changes?

So, when we talk about very speculative and abstract things like the transcendental common layer of intersubjectivity in Merleau-Ponty and Husserl, to me this is important because what interests me is what we can derive from this for clinical work, how to refine our technical tools. Some people, like Donna Orange, would ask: 'Isn't this is too abstract?'. No, it isn't. Freud can be very abstract... What about his metapsychology?... never heard of Vorstellungen repräsentant des triebes or of primary repression?

CMA:You make a clear difference between BFT and psychoanalysis oriented by Freudian principles. There seems to be a line of thinking that allows you to view phenomena like masochism and envy with very different lenses than the traditional ones.

You don't need to draw away pieces
of other models or psychoanalytic
wisdom, even if when working
clinically I think you need to be
coherent and be capable to.justify
how you listen, why, what you do,
what is your theory of therapeutic
action... So, it's not that I could
ever embrace a naif attitude of
eclecticism... immediately I would
see the contradictions.

You don't need to draw away pieces of other models or psychoanalytic wisdom, even if when working clinically I think you need to be coherent and be capable tojustify how you listen, why, what you do, action... So, it's not that I could
ever embrace a naif attitude of
eclecticism... immediately I would
see the contradictions.

GC: First of all, yes, you emphasize how different this seems from classic psychoanalysis. It may seem that Bion came from another planet, but it's not the case. Why? To know why, we need to do our homework with Melanie Klein. The linking point between classic psychoanalysis and all those concepts of death drive, resistance, regression, etc., which in fact I do not use, even if they are always in the background. I love to read Freud and I published many papers where I discuss his. You don't need to draw away pieces of other models or psychoanalytic wisdom, even if when working clinically I think you need to be coherent and be capable to justify how you listen, why, what you do, what is your theory of therapeutic action... So, it's not that I could ever embrace a naif attitude of eclecticism... immediately I would see the contradictions. If you are suspicious, you are or you are not, and this is a big division. Anyway, if you do your homework with Melanie Klein, it's very easy to understand. If you read Klein you don't find the word 'dream', you do find it here and there, but not as a true theoretical issue, which is astonishing. In Hinshelwood Dictionary of Kleinian Thought you find half a page on dream. The first time I saw it, I couldn't believe my eyes. But I come to realize that it is because for Melanie Klein dreaming is play.

In child psychoanalysis the child does not tell about his past, you cannot give transference interpretations, even if for Kleinian psychoanalysts there was this use of so-called deep interpretations. Nowadays we would think that the child could only listen to their music as a vehicle of the analyst investment. In the end you have all the factors of the post-Bionian way of working, meaning that what you do is trying to increase the capacity for symbolization, and you do this through play. In BFT, as in child psychoanalysis, both actors are on stage, all that time they are 'playing', in fiction... this is the meaning of concept like transformations in dreaming or in hallucinosis. Then, the real model of how we work in field theory is play. In play, you are engaged, you are not there as just a blank screen. All is in the fiction. You are not primarily looking for contents or reconstruction. With Klein, you can understand immediately what we mean when we say that all dialogue can be seen as play and shared dream. Indeed, this isn't but a trick to remind ourselves that we should always ask ourselves, why now, why this, what is the unconscious meaning of it?

CMA: And about masochism? How do you see it?

GC: Some years ago I published a paper in JAPA, about masochism, called "Masochism and its rhythm". There is a way to see masochism as different from a blind repetition of death drive. This explanation does not satisfy me, precisely because I work with a different concept of unconscious. To me, masochism is like a rehearsal at theater. It is repetition but aimed at giving a better meaning to what matters to you consciously and unconsciously. So, it is a completely different way to look at masochism. But, when in a session a 


\section{Envy is a kind of fever, it signals} that someone is missing something that is very important to them. So it should not be seen as a sin, as the Catholic church tells us. If you see it as a sin, as if the patient is bad because of his desire for omnipotence and wants to take advantage of you, you are not understanding the patient. The envious patient is someone who is dying of thirst, because he is in the desert and has no water to drink. You have to give him water, not hit him by saying he is envious and bad or wrong. Like shame, envy is the thermometer of the quality of the relationship. patient tells you narratives about his masochism, here of course we enter in the dream of the session. Immediately 'masochism' becomes a character in the field that hypothetically is expressing what is the quality of the emotional linking in the here and now.

I could give you another little example. A patient tells you that she suffered a real trauma in the past. She was abused at ten years old.You understand that, react humanly, keep in mind all theories about what trauma can do, etc. But the last lens that you should use, which is the most meaningful to me, is the Why this, why now? Who is 'abusing' who here? Are we both being prevaricating on each other?

'Abuse mode' in the session could be a lack of emotional availability... could be many subtle things that are narrated through recollections about traumas and so on. Is it a matter of overlooking the past or the reality of the trauma? Not at all. It depends on what your main goal is.

If it is to develop the capacity for thinking and for symbolizing, then the lens that gives me a picture of what is happening of a higher possible level of resolution is the meetings of the mind. If I use the electronic microscope, it's not that I neglect the optical microscope. Is that in that moment I choose this tool and not another tool. I know this can be seen as too radical but is very coherent and it's very logical. If the unconscious is always speaking, then it is speaking also when the patient is telling you about the highway that was closed or the trauma that he suffered in the past. And again, the basic postulate is that, no matter what is the narrative, we are going to look at it as a shared and as a clue about the quality of the emotional linking.

If you go back to Beyond the pleasure principle, you will see in that incredibly beautiful book, Freud says that dream-work tries to take us from Shreck, which can be traumatic, to Angst, 'just' anxiety or fear. I love this essay very much because Freud shows already a beautiful understanding of the transformative function of dreams which is very much in agreement with Bion's and post-Bionian's view. In that paper, he aligns traumatic dreams, masochism and the beautiful pages about Ernst playing with cotton reel game. Why does Freud line them up? Because he is telling that they have something in common. What? Precisely, this transformative quality. When Ernst draws away the toy (the object, the mother), and then he keeps it back, what is going on there? Is he masochist because he draws away the mother? No, he is transforming the absence of the concrete mother into a symbol in his mind. He's learning to symbolize. This my take on masochism in the patient, not something destructive by nature.

CMA: So you view phenomena like masochism and envy through very different lenses than the traditional ones?

GC: Absolutely. Envy for Melanie Klein is linked to death drive. And also, up to a certain time, for Bion, and for Bion is difficult to understand. Why? Because you have to listen the four Bions: you have the Bion of groups, the Bion of the Kleinian essays, the Bion of the four big books and seminars, and you have the Bion of $A$ Memoir of the Future. If you re-read "Attacks on Linking", all the time Bion tells the patient that the patient doesn't want to accept the good things he his giving him. This is because of envy, this is because of death drive and there is this kind of internal explosion of the invisible visual hallucinations - precisely, the attack on linking. He never considers the possibility that he might be the one who is attacking the patient with his disorganizing interpretations. So, this is very Kleinian... And nonetheless it is a brilliant essay, not only from the Kleinian perspective, but also for all the things that can be glimpsed that prepare for future developments in his thinking.

So, envy sounds completely different to me. I was discussing this yesterday with a colleague who wants to write about envy. Envy is a kind of fever; it signals that someone is missing something that is very important to them. So, it should not be seen as a sin, as the Catholic church tells us. If you see it as a sin, as if the patient is bad because of his desire for omnipotence and wants 
to take advantage of you, you are not understanding the patient. The envious patient is someone who is dying of thirst, because he is in the desert and has no water to drink. You have to give him water, not hit him by saying he is envious and bad or wrong. Like shame, envy is the thermometer of the quality of the relationship.

CMA: In "Attacks on Linking” Bion described how destructive aspects of personality affect links between psychic elements. How do you think about destructive parts of the mind in your psychoanalytic work?

GC: We can think of destructiveness or aggression in different ways. Aggression is either primitive, animality, wild crowd, as Freud would say, needing a police force to contain it; or a result of frustration. It's a big division in psychoanalytic thought. Of course, pathological aggression is not the healthy capacity for self-assertion. Maybe I'm too optimistic, I don't know, but for me, aggression always comes from frustration. By the way, there's something wrong when Freud seems to be sort of idealizing, for example, 'animal' sexuality, where he says that somehow civilization is based on the repression of sexuality.

I think he's confusing reproductive behavior in animals with human sexuality. Animals don't have sexuality. So, in the same way that we repress sexuality, we also liberate (human) sexuality. The same with violence. Our violence is not animal violence. We liberate our specific ways of exercising violence. Foucault and Girard address this same criticism to Freud. When we look at the animal as a model it is very easy to forget our specificity, which is given by language and self-consciousness. As some neuroscientists do, you cannot study animal perception, for example mirror neurons, and say that this explains human perception. No, because human perception, as Merleau-Ponty writes, is the unconscious; that is, it is also linguistic, cultural, social, political, etc. A short circuit is triggered every time we reason in this way.

BRF: And what about the place of sexuality inside the analytic room. How do you deal with it?

GC: Well, I think I have already answered that question, you see. Of course, sexuality is very important in psychoanalysis, we know the whole story. But perhaps we have to ask why sexuality is so important in people's lives. What would you say?

BRF: From a relational point of view, maybe it is because it has to do with pleasure in bonds and intimacy between people.

GC: Yes, that's right, but it still is too general. Why is it so dangerous?

CMA: Maybe it is because it has to do with the balance between being too much close or too much distant.

GC: Yes, of course, I would say that intimacy (L) never comes without the fear of betrayal and abandonment $(\mathrm{H})$. The point is that every time you feel gratified because you have gained more intimacy, your fears of being betrayed and abandoned, destroyed by this relationship, also grow. That's why sexuality is important in people's lives. But from a BFT perspective, it is the 'sexuality' in the analytic room that matters, not the sexuality that you can talk about elsewhere. In the analytic session, I don't see why a certain narrative content, for example sexual, should be privileged over another. At the theater everything is theatrical, that is 'fictional'.

However, we must remember that this may be your point of view but not necessarily that of the patient. Consider that in the example of the blocked highway that event is real, but in the session, we can feel it as a dream. But this is not the patient's perspective. So, because it's always a special event, we have to consider the formal aspect of what it means to tell another person a dream or to talk about intimate things. By the way, in my perspective, the analytic dream is not the dream that the patient had at night, but the telling of the 
dream in the here and now, which, again, is a shared event. The same applies to sexuality.

Another key point is that even if this is our theoretical perspective, and if these are the tools, we use to be receptive to the discourse of the unconscious, we should not pay too much attention to interpreting. The whole thing would become a kind of perverse decoding of the conversation. Absolutely not. In this way, we would not understand what Bion means when he says that we must listen without memory, desire, and understanding.

This basically means that you have to do your homework, understand the principles, the basic postulates, be able to tell someone the differences between models and concepts, explain why you choose to do this instead of that, and at the same time give yourself the space and time in the analytic situation to be surprised by the moment when this concept or perspective spontaneously comes back to you. This is the only way to allow the 'selected fact', in Bion's jargon, to pop up. An event, something, a feeling, an image that gives you the idea that perhaps you are sensing something true about what is going on in the session. As Walter Benjamin says of artistic creativity, this is the art of shocking. But it is a "happy" shock. It's a shock that is immediately contained by the fact that it gives meaning to the experience. So, for me, it's important to immerse yourself in the dialogue for a while, one session, two or three sessions, whatever, even staying in the naively realistic way of seeing things.

The important thing is that sooner or later you wake up from this dream/illusion of reality and ask yourself, 'Um, what did we say or do here?'.

BRF: I often hear in your speech a group dimension in the use of the word "we", in the questioning of what "we are doing together", when you refer to the analytic encounter. Perhaps what you are telling us that the concept of transference and countertransference still belongs to the division between self and other present in the relational model? If so, is your proposal that we should add another vertex of analysis regarding analytic phenomena, beyond what transference and countertransference allow us to access? Is that the case?

\section{There's something wrong when} Freud seems to be sort of idealizing, for example, 'animal' sexuality, where he says that somehow civilization is based on the repression of sexuality. I think he's confusing reproductive behavior in animals with human sexuality. Animals don't have sexuality. So, in the same way that we repress sexuality, we also liberate (human) sexuality. The same with violence. Our violence is not animal violence. We liberate our specific ways of exercising violence.
GC: This is a good question. First of all, I'd like to answer something that perhaps Bruno asked when he said that there are different ways of understanding the field. People tend to believe that the field model is the one proposed by the Barangers. Well, yes and no. Because the Barangers were saying that the 'bastion', the bulwark is something that is constituted by the participation of the analyst and the patient. So, it is something that would not exist if patient or analyst weren't not both there. But to me, their approach seems very similar to the concept of enactment. The fate of the bulwark is to be eliminated. In this way I could say that in Barangers' description of the concept the field is limited to the negative of the analytic field. On the contrary, what I mean is a much broader notion of the field as the metaphor that helps, despite its positive or negative valence, to attune to the unconscious life of the analytic couple. Nowadays that field theories are having much success everywhere, we have this proliferation of the concept of field. It's like parsley, which you can put everywhere. Okay, you can do that, but field theory comes from Lewin, from quantum physics. It means precisely that there is a system whose emergent properties cannot be explained by any of the properties of the parts of the system if we look at them in isolation. So when I see people using this metaphor and then there is not this field that works like this in what they are showing, I ask, why bother with the effort and struggle to use the concept of a field? It's just that what you're describing is not the concept of field, despite the use of the word. In any case. Can we be eclectic? Use different models? In different patients or with the same patient at different times? I'm a little skeptical about that. Why? For example, people always ask me, Giuseppe, but how can you say that this reverie you have is not a countertransference phenomenon?

First of all, the term reverie is getting a little confusing. That's kind of what happens to the concept of countertransference. Because it seems that people 
Another key point is that even if this is our theoretical perspective, and if these are the tools we use to be receptive to the discourse of the unconscious, we should not pay too much attention to interpreting. The whole thing would become a kind of perverse decoding of the conversation. Absolutely not. In this way, we would not understand what Bion means when he says that we must listen without memory, desire, and understanding. have forgotten that countertransference is an unconscious phenomenon, but instead we see an indiscriminate use, as if everything the analyst feels is countertransference. So today it also seems that everything can be a reverie, but a reverie is like a dream while we are awake and by definition is something we experience in a state of passivity other than associative thinking. When a reverie emerges, it appears as a cut and has no clear connection to what is happening or being said. Furthermore, the capacity for reverie is more akin to Winnicott's primary maternal concern than to mere reverie. So, people ask me, how can you say that this reverie is not a countertransference phenomenon?

And then I have to say that we should start having clear notions of epistemology. If my initial postulate is different, if my initial postulate says that what happens is co-created and shared, then that is no longer the appropriate question. Because, by definition, if my hypothesis pushes me to see everything as shared, there is no logical space for a phenomenon to be conceptualized as countertransference. That conception of the same phenomenon corresponds to another postulate. But now, why do I say that we have to have a clear sense of epistemology. Because we cannot prove a postulate. Not even in mathematics or geometry. How do we know if one postulate is better than another? From what allows it us to recognize, think and do 'downstream'. Therefore, we cannot simply transfer a concept into another theoretical framework. Because even if it has the same name, a concept only exists in a network of concepts that gives it its meaning.

So, my answer is that yes, a reverie can be seen as a countertransference phenomenon, absolutely. But in another epistemic framework, where the postulates are different, by definition, it cannot, not in BFT. The issue is that you have to accept that either you see the profiles or the vase.

CMA: In 2014 you wrote an important article on the influences of Romantic aesthetics on Bion's work. In your latest book, The Hour of Birth, you have extended these ideas to explore the origin of the psyche and its ongoing development through life. Could you tell us a little bit about that?

GC: Ogden says that, in human history, Freud invented two new ways of relating to the other, which are the analytic session and the supervisory session. This is wonderful! The Freudian funktim is wonderful. No one else can say these things using our own vertex. So, psychoanalysis is a technique of treatment, it is a theory of mind, but it is also a method of inquiry into psychic processes. It is also the foundation of critical theory and new way of doing art criticism. Psychoanalysis is a lot of things, and we should be proud of it. We know that Freud was the first to relate psychoanalysis to art, but over time classical Freudian criticism has become a bit obsolete. Putting the artwork on the couch, so to speak, doesn't work because you lose the most important part of art, which is the formal aspect. However, psychoanalysis has a lot to say about this, and vice versa. Why? Precisely because of what we said earlier. We said that the infant does not speak yet. What is the infant? The infant is, from one point of view, like an abstract painting. It is a system of sensations, affects, rhythms. A child moves from the womb to what Kristeva calls a semiotic chora, a dynamic space that, if "happy" enough, generates subjectivity. So, you see how important the aesthetic experience in art is to understand how we are born and continue to be born throughout our lives. Why do we seek art so much in our lives? Because we always want to continue to be born with new ideas, and especially new embodied ideas. We aim at enlarging our power to act, our freedom. And that's why I call it 'the hour of birth'.

BRF: I would like to ask you what are the continuities and discontinuities between your concept of the sublime and that of the aesthetic conflict of Donald Meltzer? 
What is the infant? The infant is, from one point of view, like an abstract painting. It is a system of sensations, affects, rhythms. A child moves from the womb to what Kristeva calls a semiotic chora, a dynamic space that, if "happy" enough, generates subjectivity. So you see how important the aesthetic experience in art is to understanding how we are born, and continue to be born throughout our lives. Why do we seek art so much in our lives? Because we always want to continue to be born with new ideas, and especially new embodied ideas. honestly admits having found it in Bion. Indeed, at the beginning of my chapter I remind the reader of this fact. I also had the good fortune to know Meltzer personally, because he used to come to Italy to supervise cases when I was a student trainee in psychiatry. He was the first to really comment on Bion's contributions and expand on Bion's ideas in a very original way. I think Meltzer has been somewhat sidelined lately. I don't know why, but he is a very, very interesting thinker.

So, what is essential about the birth of the psyche, when there is only the preverbal experience of breast and non-breast, of thing and no-thing (as opposed to the nothingness, that means pure terror)? It is the rhythm, as in little Ernest's fort-da game; the being and the non-being, the trace of the gratifying experience of contact with the breast, which then becomes a symbol or word that allows one to tolerate absence; but then also, of course, being able to experience gratification in presence again, because otherwise a person would fall into the abyss of non-sense.

Aesthetic conflict is the same thing. One has to tolerate the fact that we don't know what is beyond the realm of our conscious experience. We cannot know what is in the mind of the other, or in the mind of the mother, even if she is beautiful and smiling. In our analytic work, it is always the patient's question, 'Do you love me because you love and accept me or because I pay you?'. But it's reciprocal, notice, it's a field even the analyst might ask: 'Is the patient grateful to me, sincerely grateful because I helped him or not? So, does he love me or was it just an instrumental relationship?'.

Yesterday I had to console, calm down a young patient of mine in analysis who was abruptly abandoned by his patient. He was in a critical emotional state. So, it is always mutual, intimacy always brings the fear of betrayal and abandonment. Thus, the concept of aesthetic conflict, redefined by Meltzer, helps us as a tool to understand the various related issues of the emergence of meaning, in clinical work, theory, and art criticism. So, yes, my interest in the sublime is a way to continue my inquiry into aesthetic conflict.

BRF: Could you tell us something about your notion of embodied sublimation? Does it anticipate the emerging process of abstraction from concrete reality in which subjectivation consists of?

CG: Absolutely, and it's always intersubjective, it's always social. This is another very important aspect. Sometimes they ask me 'Yes, Giuseppe, but if you say that everything is co-created and co-generated, where does the subject go?'. Actually, the subject does not go anywhere, because the subject is there, the point is that the subject, the empirical self, as an isolated entity that moves, that takes initiative, is what is visible, is the conscious subject. Psychoanalysis is about the invisible, it is about expanding the invisible fabric of our intersubjective flesh. If subjectivity and intersubjectivity are the two sides of the same coin, this means that if our intersubjectivity expands, then it is also our subjectivity that is strengthened. There is no opposition between intersubjectivity and subjectivity. Intersubjectivity, as an expansion of one's internal sociability, is what allows for multiple points of view on a topic or subject, which is by definition being psychologically mature. Conversely, blending in with the crowd means that you have less connection to the infinity of others and language, and that you must dogmatically attach yourself to one perspective. It is in this condition, or moment, that our intersubjectivity is limited. Therefore, expanding intersubjectivity means at the same time expanding subjectivity in the subject, because they are dialectically related. This is also why it is important to develop the concept of intersubjectivity. To better understand this dialectical game and not get stuck in a naive and dichotomous view of the subject and intersubjectivity. What's more, this is precisely a wonderful model of what happens when psychological distress arrives. It comes, as Bion and Winnicott have wonderfully shown, when the child faced with an object that is not available, must somehow develop a false self, obey a cruel superego and live in a world of tyranny, not in a democratic 
world; and he must stick to a single vision that is dictated by the object. This is not the realm of freedom.

Given this, by 'sublimation' I do not mean the classical Freudian concept; if anything, I try to see, for example in my book Sublime Subjects, how it can be made to dialogue with the concepts of the sublime, which comes from the field of aesthetics, and of sublimation of the flesh, which we owe to Merleau-Ponty-Ponty. In essence, I am trying to explore the field of intercorporeality, that is, the processes of abstraction (of subtraction of the concrete) that take place on the corporeal plane and not yet directly on the linguistic one. For example, an affect or a habit — as we know, already a subject of study for Hegel—from a certain point of view can be considered an embodied 'concept'.

CMA: The SPP will celebrate its 40th anniversary. What would you like to convey to young psychoanalysts in our Society?

GC: I could say, as you can clearly see that after almost half a century of being interested in psychoanalysis in one way or another, my enthusiasm has grown with time. I feel that this is an absolutely vital, beautiful discipline, and it is worth devoting my life to it, but we need a theoretical and ethical re-foundation of our theories along the lines we have been saying. Then, we

We need to put our young
colleagues in a position to develop
careers and become creative in
psychoanalysis, not infantilize them
anymore and say that at forty-five
years old they' re still kids. And we
seem to have a peculiar biology.
While everybody else retires at
seventy from institutional work
and then goes on to do other
things, we sometimes start in our
seventies-for example, to teach.

We need to put our young colleagues in a position to develop psychoanalysis, not infantilize them anymore and say that at forty-five years old they're still kids. And we While everybody else retires at
seventy from institutional work
and then goes on to do other
things, we sometimes start in our
seventies-for example, to teach. need to reform our institutions. At the recent Congress of the Mexican Society, I was asked to say something about the future of psychoanalysis. I said that we only have a few centuries left, but that we need to reread the Kernberg essays, which are beautiful, about how we are so capable of destroying the creativity of candidates and we are so capable of functioning as a church, not as a scientific institution.

The last one is called "How to Avoid the Suicide in Psychoanalytic Institutions." If a former president of the IPA, and a creative and intelligent theorist, says it, we must take it seriously. We need more transparency, more democracy, to accept the normal rules for the evaluation of scientific work (the $h$-index), without appealing to the defense of local traditions, which is just a way to avoid confrontation. Nowadays, if a cardiologist or a psychiatrist said, 'This is our tradition and we do as we like', we would laugh at them.

We need to put our young colleagues in a position to develop careers and become creative in psychoanalysis, not infantilize them anymore and say that at forty-five years old they're still kids. And we seem to have a peculiar biology. While everybody else retires at seventy from institutional work and then goes on to do other things, we sometimes start in our seventies-for example, to teach. I know of only one other institution where the career is tied to unquestioning loyalty to the institution and to age: the Church. Basically, I believe that if we don't reform our institutions there will be a risk of being delegitimized by the other institutions in our society. If we blindly claim to defend what can no longer be defended, we will be simply marginalized.

So, what I'm saying is that psychoanalysis is worth devoting your life to, it's really exciting and beautiful, but only if our institutions really show a willingness to reform themselves. That becomes very concrete for young analysts, a matter of life choices. For instance, I'm well aware that I didn't follow an academic career that was already there, because I somehow idealized psychoanalysis, which is normal; still, at the time I started, psychoanalysis had a very different place in society. We lost many positions. We have to ask ourselves why. I don't think this is just my sentiment.

CMA E BRF: Thank you very much Dr. Giuseppe Civitarese, for this honest, interesting and playful conversation. It was for us an honor to interview you and get to know in detail your thoughts. We are certain that this interview will be of great relevance and arouse the interest of Portuguese psychoanalysts. $\Omega$ 